\title{
Formation of Research Programs in the Field of Strategic Planning of Socio-Economic Development
}

\author{
Lyalya Edilsultanova*, Elena Mazhigova
}

Chechen State University named after A.A. Kadyrov, Grozny, Russia

${ }^{*}$ Corresponding author. Email: piter_1968@bk.ru

\begin{abstract}
The emphasis of scientific and methodological support of the strategic planning system as a mechanism of public administration is shifting towards the formation and implementation of unified algorithms for analyzing a huge array of information contained in strategic planning documents, the widespread use of software and mathematical tools for simulating the dynamics of complex socio-economic systems, methods for assessing the state of industries economy and social spheres and making management decisions on the choice of optimal development scenarios, overcoming the identified risks and threats. In this regard, it seems advisable to strengthen the mechanisms for the formation of topics of fundamental and applied scientific research in the field of economics and public administration, creating a scientific and methodological environment for the digital economy, a regulatory and legal framework for the widespread use of "big data" algorithms and artificial intelligence technologies in the system of strategic planning of social economic development and national security.
\end{abstract}

Keywords: strategic planning system, socio-economic systems, digital economy, strategic planning, ensuring national security.

\section{INTRODUCTION}

Obviously, the research topics are interdisciplinary in nature with a focus on practical results and the widespread use of IT technologies, which indicates systemic changes in the organization of scientific research, an increase in customers' demands for their results. In order to increase the efficiency of interaction between government bodies and the scientific and expert community in the formation of comprehensive research programs in the field of strategic planning of socioeconomic development and ensuring economic security, it is proposed to establish an appropriate conceptual apparatus, as well as to form functional criteria reflecting the interests and requirements of the state system. management to the topic, purpose and expected results of the specified research works and services. Before proceeding with the formation of these functional criteria, it is advisable to define the term "state needs in the field of scientific research", which until now does not have a strict legal interpretation. Actually, the legal uncertainty regarding this term is associated with the practical experience of implementing federal target programs. As you know, the program activities of the FTP involve significant amounts of budgetary co- financing of exploratory and applied R\&D for the development of the scientific and technological reserve and the national technological base, the development and modernization of complex science-intensive products. However, in the future, these products are produced by legal entities of various property and legal forms and are sold in the external and internal markets for the purpose of making a profit [1]. That is, the budgetary financing of the indicated R\&D has the character of state support for industry enterprises to create samples of high-tech equipment with long periods of development, testing and promotion on the market.

\subsection{Solving the Problems of Scientific and Methodological Support of the Strategic Planning System}

In order to effectively solve the problems of scientific and methodological support of the strategic planning system as a mechanism of public administration, we believe it expedient to establish the following definition: authorities in order to directly improve the mechanisms and solving problems of public administration in the sphere of competence, enshrined in accordance with the legal acts, on the principles of strategic planning "[2-3]. 
As a consequence, the functional criteria for the formation of a thematic list of exploratory and applied scientific research in the field of economics and public administration are as follows [4]:

- the topics and content of applied scientific research directly corresponded to the key tasks of improving the mechanisms of public administration, established by the basic documents of strategic planning;

- the terms of reference, the implementation mechanism and the results of research work directly provided state needs in the sphere of competence of the state authority - the customer of the work;

- the results of scientific research represented a set of new knowledge and practically important information on the topic of research, as well as a necessary and sufficient list of tools and recommendations for the operational use of the results in the practical activities of the customer [6].

The ideal option for interaction between the customer and the performer of research work in the process of acceptance procedures is the willingness to consolidate the main results of research in the format of a plan ("roadmap") of measures for their implementation in the activities of the customer, during the preparation of which possible implementation risks. A possible illustration of the application of the approaches described above to the formation of a list of scientific research directly aimed at meeting state needs, may be the formation of a federal system of risk management in the field of economic security of the Russian Federation (hereinafter - FSSR) [7]. The decree of the President of the Russian Federation established that the subjects of the FSMS are federal executive bodies, state authorities of the constituent entities of the Russian Federation, the Central Bank of the Russian Federation, state corporations, companies and other industry organizations that carry out activities to solve the functional tasks of the FSMS in accordance with the competence and powers, enshrined in their title documents. It seems that the main tool for continuous monitoring and analysis of the state of the economy and social spheres within the competence of the subjects of the FSMS are software systems for simulation modeling [4], which contain:

- a block of presentation of the main factors and components of ensuring economic security in the economic sector, characterized by quantitative indicators (the subject field of the factor model);

- a structured model of external influence on the block of main factors, containing a system of digitized connections and interaction potentials to identify the most significant levels of the subject field's response to external influences;

- a comfortable interface for interaction with the model, which forms possible scenarios of the dynamics of economic security under the influence of various events and a quantitative assessment of the values of indicators of the state of economic security.

In this case, the values of the indicators are set at the beginning of the calendar year, reduced to relative values with normalization in the interval from zero to one. The potentials of connections between the factors (elements) of the subject field are determined on the basis of the coefficients of pair correlations established from the materials of statistical observations, which ensures their absolute objectivity. The balanced digitized factor model is visually a three-dimensional diagram that characterizes the initial state of the subject field [6].

\section{RESULTS AND DISCUSSION}

The process of imitation modeling consists in analyzing changes in the relief of the subject field under external influence, identifying the most vulnerable elements of the subject field, interpreting the identified "painful" situations and searching for positive influences that return the model to its original state. The stages of simulation modeling and the sequence of operations of interaction with the model include: - digitization of an external event (series of events), actually occurring or potentially possible, and the introduction of external disturbance into the simulation model using the interaction interface; - analysis of changes in the relief of the subject field relative to the initial balanced state, identification of the factors most susceptible to impact; quantitative assessment of individual deviations of the values of factors from the initial state (integral assessment of the disturbance of the relief of the subject field as a whole, characterizing the change in the state of the modeling area) [7];

- digitization and input using the interface of positive influences (public policy measures) aimed at reducing the disturbed state of the subject field, at introducing the values of the subject field factors into an acceptable framework;

- expert analysis of the results of negative and positive impacts in order to formulate the main risks and measures of state policy to counter them (the reverse process from digitized indicators to the development of management decisions).

The given description of the software package and the simulation modeling mechanism as a whole reflects the methodology of expert analysis of large amounts of statistical observation data in order to identify negative trends, critical connections between events and factors, and develop recommendations for countering them [8]. The use of IT technologies makes it possible to significantly (by one or two orders of magnitude) expand the number of factors taken into account, ensure the objectivity and completeness of the analysis, efficiency in developing management decisions to counter 
identified negative trends, threats and risks. At the same time, it should be noted that the role and place of an expert as a human factor in scientific research has changed - from direct analysis of information arrays to research that ensures the functioning of the simulation model as a tool of public administration [11].

\section{CONCLUSION}

The most important role of the strategy of socioeconomic development makes increased demands on the quality of its development. One of the quality control mechanisms for the development of any plan, including a strategic one, is the assessment of its effectiveness, carried out following the results of its implementation [9]. However, in relation to regional strategies, the current legislation (Federal Law "On Strategic Planning in the Russian Federation") obliges to assess only the achievement of the goals of socio-economic development. It should be emphasized that the formation of a list of scientific research to ensure the creation of the FSMS is in one way or another associated with the formation of complex creative teams, whose members have the necessary interdisciplinary competencies, knowledge and practical skills in specific sectors of the economy, social spheres and areas of national security. One way or another, the problem of the formation of a specialized scientific school, focused on scientific and methodological support of the system of state and corporate governance in the field of economic security, acquires an urgent character [10]. Actually, similar approaches, principles and mechanisms should be used in the formation of programs and lists of scientific research focused on meeting state needs in accordance with the goals and objectives established in the basic documents of strategic planning.

\section{REFERENCES}

[1] D. G. Gaynulin, V. V. Voronin, General principles of forming a risk management system in the field of economic security, 2018 p. 154.

[2] A. Braverman, A. Saulin, Integral assessment of enterprise performance, 2019 pp. 108 -121.

[3] R. Brailey, S. Myers, Principles of Corporate Finance 2020 p. 132.

[4] A. Voronov, S. Rubanov, Sustainable development of the enterprise as a strategic goal of marketing, 2018 pp. 31-37.

[5] E.V. Korchagina, Economic sustainability of an enterprise: types and structure. Problems of the modern economy 3(15) (2018) pp. 68-71.

[6] Campbell Scientific Inc., Bowen Ratio system. Logan, UT USA, Instruction manual 2020 p. 30.
[7] W.A. Dugas, Micrometeorological and chamber measurements of $\mathrm{CO} 2$ flux from bare soil. Agricultural and Forest meteorology 2018 pp. 115128.

[8] A.S. Salamova, The theoretical foundations of institutionalism at the stage of accelerating globalization of international economic relations, 2020 pp. $349-356$.

[9] J.J. Andrea, C. Burns, J. Touza, Renewable Energy as a Luxury? A Qualitative Comparative Analysis of the Role of the Economy in the EU's Renewable Energy Transitions During the 'Double Crisis'. Ecological Economics 142 (2020) pp. 81-90.

[10] J. Yang, F. Zhang, X. Jiang, W. Sun, Strategic Flexibility, Green Management, and Firm Competitiveness in an Emerging Economy. Technological Forecasting and Social Change 101 (2018) pp. 347-356.

[11] K. Murtazova, M. Abdulkadirova, The Consumer Market in the New Economy, 2021 pp. 2-9. 